16 a 18 de outubro de 2019 - Campinas | Brasil

\title{
ESTUDO DO MÉTODO DE FLUIDODINÂMICA COMPUTACIONAL (CFD) APLICADO A PROCESSOS AMBIENTAIS.
}

\section{Nathalia Morgana Rissi, Diener Volpin Ribeiro Fontoura, Simone Andréa Pozza.}

\section{Resumo}

Uma forma de propiciar o entendimento dos fatores que influenciam na qualidade do ambiente é o uso de ferramentas computacionais. A técnica de fluidodinâmica computacional (CFD) tem sido uma alternativa para permitir a busca de soluções, por meio de simulações que possibilitam o estudo de diferentes cenários que seriam onerosos se houvesse a necessidade de realizá-los experimentalmente. Assim, o objetivo deste trabalho foi realizar simulações de CFD, com o software livre OpenFOAM, para a análise do conforto térmico em um ambiente fechado.

\section{Palavras-chave:}

CFD, Conforto térmico, OpenFOAM.

\section{Introdução}

Para garantir um ambiente interno saudável e confortável é indispensável a renovação do ar limpo. Uma forma de realizar esse processo é por meio de sistemas de ventilação. $O$ uso de ferramentas computacionais pode promover a escolha e instalação dos equipamentos do sistema de ventilação de forma precisa e otimizada.

Nesse contexto, a Fluidodinâmica Computacional (CFD) apresenta-se como uma metodologia numérica capaz de realizar esses estudos. A aplicação dessa técnica permite traçar estratégias, sendo uma solução de baixo custo e alta flexibilidade 1 .

Assim, o presente trabalho consiste na aplicação de CFD para o estudo da interação homem-ambiente em locais fechados. Foi avaliado o conforto térmico, por meio da influência do fluxo de ar e da transferência de calor. O local escolhido para essa análise foi o Restaurante Universitário da Unicamp, localizado no campus I de Limeira.

\section{Resultados e Discussão}

Foram analisadas as variáveis de pressão, temperatura e velocidade do ar para avaliar o conforto térmico do local escolhido, com o auxílio da ferramenta OpenFOAM ${ }^{2}$, um software livre. A Fig. 1 apresenta o resultado obtido pela simulação para a velocidade do ar.

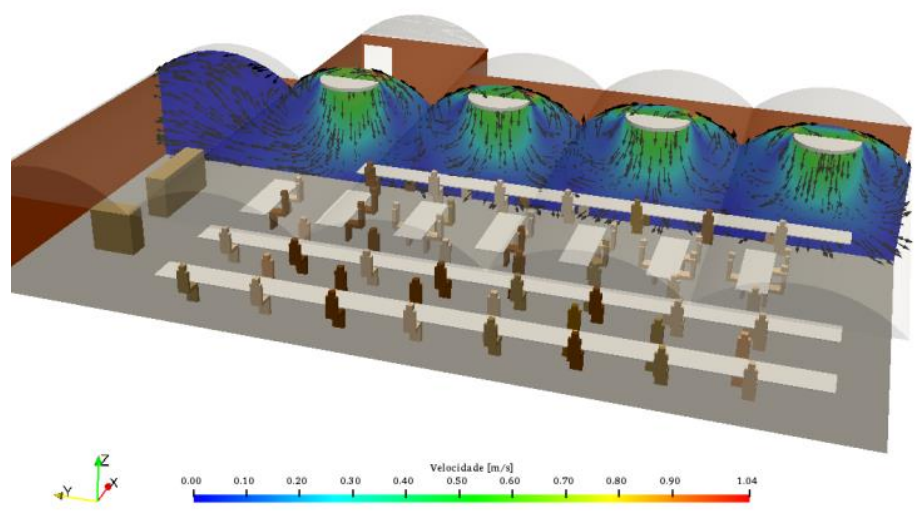

Figura 1. Simulação térmica na condição inicial.
Foram estudadas possíveis alterações no sistema de ventilação com o intuito de melhorar o conforto térmico do ambiente. Uma das sugestões foi a substituição dos oito ventiladores existentes por quatro exaustores para tornar a renovação do ar mais eficiente. A Fig. 2 apresenta o resultado obtido pela simulação para a velocidade do ar conforme a modificação proposta.

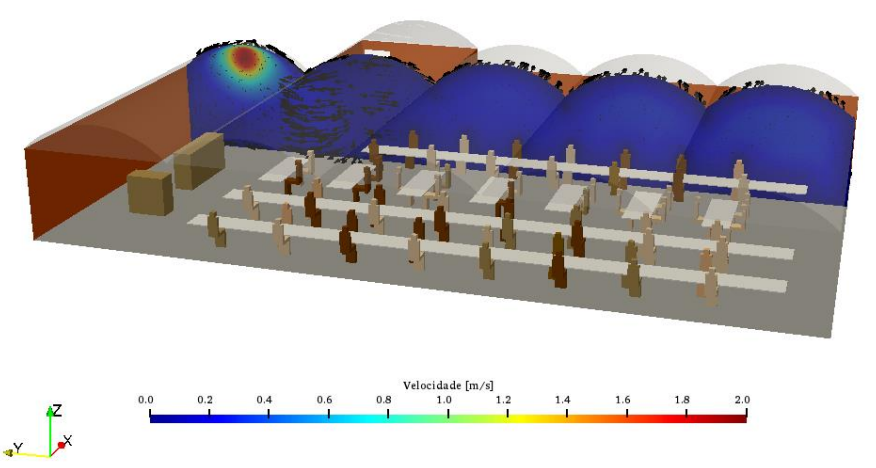

Figura 2. Simulação do fluxo de ar após alterações.

\section{Conclusões}

As simulações realizadas permitiram maior compreensão da situação atual e das possíveis melhorias que podem ser implementadas no ambiente do local escolhido. A ferramenta permite maior flexibilidade no estudo da solução de melhor viabilidade técnica.

\section{Agradecimentos}

Ao Conselho Nacional de Desenvolvimento Científico e Tecnológico (CNPq) pela concessão da bolsa de Iniciação Científica Tecnológica e a Tau Flow pelo auxílio na realização da pesquisa.

\footnotetext{
${ }^{1}$ Jiyuan Tu, Guan-Heng Yeoh, Chaoqun Liu. Computational Fluid Dynamics, $2^{\text {nd }}$ Ed. Butterworth-Heinemann, 2013, Pages 1-29. ISBN 9780080982434.

2 OpenFOAM. User Guide. versão v1812. OpenCFD Limited, 2014a. Disponível em: <https://www.openfoam.com/documentation/user-guide/ userch1.php\#x3-20001>. Acesso em: 2 de fevereiro de 2018.
} 